\title{
An Infectious Disease Day-Hospital service in a metropolitan area of Northern Italy. Evolving assistance features in the last fifteen years (1994-2008)
}

\author{
Roberto Manfredi
}

From $16^{\text {th }}$ International Symposium on HIV and Emerging Infectious Diseases

Marseille, France. 24-26 March 2010

\section{Background}

Aim of our study is to evaluate the frequency and features of admissions performed at an Infectious Diseases Day-Hospital service at S. Orsola Hospital, Bologna, Italy.

\section{Methods}

A retrospective evaluation of all admissions of the last 15 years (1994-2008), was performed.

\section{Results}

Before the introduction of potent, combination antiretroviral treatments (cART) (years 1994-1996), the proportionally low mean number of admissions (110/year), was linked to the elevated prevalence of HIV disease, which accounted for $89.4 \%$ of Day-Hospital hospitalizations, their recurrence, and their prolonged duration. Immediately after cART introduction, the number of Day-Hospital admissions showed a significant increase, from 171 (year 1997), to 318 (2002),338 (2003),347 (2004),331 (2005),356 (2006), 341 (2007), and 378 (2008) $(p<.0001$ versus the pre-cART era), although this phenomenon paralleled a drop of percentage of HIV-related admissions (from 59.1\% of 1997, to a minimum of $23.8 \%$ of the year $2005 ; p<.0001$ ). While HIVassociated hospitalizations decreased, a temporal increase of admissions due to chronic liver disease occurred $(p<.0001)$. The reduction of admission duration allowed an increase of overall number of hospitalizations of each examined year $(p<.0001)$, and the mean bed occupation rate showed a continued rise $(8.2$

Correspondence: Roberto.manfredi@unibo.it

Infectious Diseases, University of Bologna, S. Orsola Hospital, Bologna, Italy in the year 2000, to maximum value of 12.0 reached in the year $2006(p<.0001)$.

\section{Discussion}

The modifications occurred at our Infectious Diseases Day-Hospital service during the last 15 years are largely attributable to the significant changes occurred in the spectrum of infectious disorders which came to our attention: from a low number of prolonged hospitalizations typical of patients with advanced HIV disease, the cART era led to a progressive broadening of the spectrum of disease, and a notable reduction of admission time. Notwithstanding this situation, no significant modification was observed as to mean weight of diagnosisrelated group (DRG) features:from a mean 1.03 rate per patient of the year 2000, to a mean 1.33 figure in the year 2008. The evolution of assistance features in a DayHospital setting, seems strictly linked to the modification of prevailing disorders. A permanent monitoring of the features of health care provision at an Infectious Disease Day-Hospital service may allow to consider significant temporal modifications, and contribute to ensure adequate assistential planning, including the eventual revision of structural, professional, technical, and funding resources.

Published: 11 May 2010

doi:10.1186/1742-4690-7-S1-P180

Cite this article as: Manfredi: An Infectious Disease Day-Hospital service in a metropolitan area of Northern Italy. Evolving assistance features in the last fifteen years (1994-2008). Retrovirology 2010 7(Suppl 1):P180. 